\title{
HAITI: LOS INCIERTOS CAMINOS HACIA LA DEMOCRACIA
}

\author{
Ana Inés López-Accotto y Javier M. González*
}

El mes de diciembre de 1995 será una fecha clave para Haití, ya que las elecciones presidenciales que proclamarán al sucesor del presidente Aristide deben consolidar el difícil proceso democratizador. El traspaso del poder entre dos presidentes elegidos democráticamente será un hecho inédito hasta ahora en toda la historia del país, a pesar de que logró su independencia antes que los países de la América hispana.

El país más pobre del hemisferio -y uno de los más pobres de la Tierra - tiene también una terrible historia política, con frecuentes cambios de gobierno, marcados por asesinatos y revoluciones. Desde su independencia de Francia, en 1804, hasta 1994, tuvo 26 jefes de Estado, de los que 23 fueron instalados por golpes militares. Una excepción fue el gobierno de Jean Pierre Boyer, que gobernó entre 1818 y 1843 . Pero tras su derrocamiento, volvieron los golpes y asesinatos. En todo el siglo XIX Haití fue víctima de un boicot internacional, ya que las potencias coloniales tenían miedo de que el ejemplo de una república negra independiente se expandiese por el Caribe.

\section{LOS DUVALIER}

La dinastía de los Duvalier gobernó Haití durante 37 años, entre 1957 y 1986 . Y lo hizo con mano de hierro: de 1957 a 1979, 30.000 haitianos fueron eliminados por el aparato represivo del régimen, fundamentalmente por los 40.000 Tonton Macoutes con que llegó a contar el régimen.

François Duvalier, "Papá Doc", había sido Director General del Servicio Nacional de Salud Pública y ministro de Trabajo y Salud durante el gobierno del presidente Dumarsais Estimé. Con el golpe militar de Paul E. Magloire, se convierte en la principal figura de la oposición y pasa a la clandestinidad. Después de la renuncia de Magloire en diciembre de 1956 , los seguidores de Duvalier participaron en la mayoría de los 6 gobiernos que se formaron en los siguientes 10 meses, de reformas populares y nacionalismo negro. Finalmente, Duvalier sería elegido presidente en septiembre de 1957.

Para consolidar su poder redujo el tamaño del Ejército y con su principal asesor, Clément Barbot, organizó los Ton-

${ }^{*}$ ) Los autores son socióloga política y periodista de política internacional, respectivamente. ton Macoutes. Sus primeras víctimas estarán entre la burguesía mulata y los militares de alto rango. Duvalier manipuló las elecciones legislativas de 1961 para poder extender su mandato. Estas y otras medidas corruptas y despóticas significaron el fin de la ayuda de Estados Unidos. En 1963 los exiliados de Florida intentaron un desembarco en la isla, pero fracasaron y la represión fue sangrienta. El régimen se endureció, promoviendo un culto a su persona, como encarnación semidivina de la nación haitiana. En abril de 1964 fue declarado presidente vitalicio. Fue excomulgado por el Vaticano en 1966 por acoso al clero.

A su muerte, en 1971, le sucede su hijo Jean Claude, "Baby Doc", que se convirte, a los 19 años, en el presidente más joven del mundo. Al principio deja hacer a su madre, la terrible Simone, y a la vieja guardia de su padre. Pero después, de manera sorpresiva, toma las riendas del poder de manera firme. Presionado por los Estados Unidos, hizo algunas reformas. Revocó a los más viejos colaboradores de su padre, liberó a algunos presos políticos y suavizó la censura. Proclamó una gradual democratización de las instituciones y afirmó: “yo haré la revolución económica”. Pero no hubo en realidad cambios importantes: no toleró la oposición política y todos los cargos relevantes, incluyendo los jueces, seguían siendo nombrados por el presidente.

En febrero de 1986, una movilización popular logró el fin de la tiranía. El día 7 de febrero, Baby Doc abandonó Puerto Príncipe y pidio asilo en Francia.

\section{EL POSTDUVALIERISMO}

Tras la caída de Baby Doc, transcurrieron cinco años hasta la celebración de las primeras elecciones libres y democráticas, que llevarían a la presidencia a Jean Bertrand Aristide. Como primer paso se constituyó un Consejo Nacional de Gobierno, con el general Henry Namphy como presidente. Era ministro de Exteriores el entonces coronel Prosper Avril, uno de los mejores amigos de "Baby Doc", que llegó a tener una oficina en dependencias del Banco Nacional de Haití para administrar las finanzas personales de Duvalier. Será un período en el que ambos militares mantendrán una sorda lucha por el poder; años en los que la represión y las matanzas fueron la respuesta sistemática a la movilización popular contra los gobiernos militares. 
El general Namphy se vió obligado a convocar elecciones, como consecuencia de presiones internas y externas. Previstas para el 29 de noviembre de 1987, fueron canceladas ese mismo día, después de un baño de sangre (al menos 34 muertos) perpetrado contra las filas de pacíficos votantes. Se atribuye la matanza al coronel Jean-Claude Paul, con órdenes secretas de Namphy, para impedir el probable triunfo de Gerard Gourgue, candidato del Frente de Concertación Nacional y abogado defensor de los derechos humanos.

Namphy volvió a convocar elecciones para el 17 de enero de 1988. La oposición calificó los comicios de farsa y se abstuvo en bloque. Sólo participó el 5 por ciento del electorado con derecho a voto. Fueron consideradas las elecciones más fraudulentas de la historia de Haití. Venció Leslie Manigat, un cientista político que en una época colaboró con el régimen de Papá Doc, abandonándolo más tarde para exiliarse y enseñar en diversas universidades de Estados Unidos, Francia y Venezuela. Frank Romain, conocido como uno de los más crueles represores de la era Duvalier, sería elegido alcalde de Puerto Príncipe.

El 15 de junio de 1988, en su afán de no seguir apareciendo como un títere de los militares, Manigat destituyó de su cargo de Comandante en Jefe del Ejército al general Namphy, con el apoyo del coronel Paul, jefe del batallón "Leopardos". Pero días después, Paul devolvió el apoyo a Namphy, en alianza con Prosper Avril, entonces jefe de la guardia presidencial. Entre los tres derrocaron a Manigat y Namphy se autoproclamó de nuevo presidente.

No duraría mucho en el palacio presidencial. El 17 de septiembre de 1988 fue derrocado por el general Avril, en un golpe promovido por un grupo de 16 sargentos. Avril nombró comandante en jefe al coronel Paul y él mismo se designó presidente, prometiendo elecciones y gobierno civil.

Todo el año 1989 estuvo marcado por la violencia, alzamientos militares y protestas de la oposición civil. A principios de 1990 la actividad de la oposición se incrementó, pese a que Avril había anunciado ya la convocatoria a elecciones municipales para el 29 de abril y a presidenciales para el 28 de octubre. La represión brutal continuaba, produciéndose asesinatos, deportaciones de activistas de la oposición y todo tipo de violaciones a los derechos humanos. Frente a las denuncias crecientes, Avril decidió a finales de enero levantar el estado de sitio, anular la expulsión de opositores y otorgar visados de reingreso para los exiliados. Días después, la ANDP, que agrupaba al Movimiento para la Instauración de la Democracia en Haití, dirigida por Marc Bazin, el Movimiento Nacional Patriótico 28 de Noviembre, liderado por Dejan Bélizaire y el Partido Nacionalista Progresista Revolucionario, de Serge Gilles, exigió públicamente la renuncia de Avril y amenazó con no participar en las elecciones previstas.

Dos meses más tarde, once partidos hicieron un llamamiento a la insurrección generalizada, alegando que el gobierno constituía un peligro público. En respuesta, Avril no descartó la posibilidad de abandonar el poder ante el agravamiento de la situación. Aunque, en una intervención por radio y televisión, se preguntó: “¿Será ése el interés del país? ¿Qué va a ocurrir si dejo la presidencia? ¿Cómo va a reac- cionar la gente, cuál será el balance?". Al día siguiente, miles de manifestantes en Puerto Príncipe se enfrentaban con policías y soldados, tras el entierro de una escolar de once años, muerta cuando la policía reprimía una manifestación estudiantil. Prácticamente todo Haití estaba sublevado. En los días siguientes creció el número de muertos. Centenares de opositores cerraron con barricadas las carreteras norte y sur que convergen sobre la capital. El general Avril formó entonces un gobierno cívico-militar de crisis.

El 10 de marzo, como resultado de un acuerdo negociado durante horas por los embajadores de Estados Unidos y de Francia, Avril entregó el poder al comandante del Ejército, general Herard Abraham. Este anunció que restablecería la paz en un plazo de 72 horas en el que transferiría el poder a un gobierno provisional para que organizara elecciones democráticas. El 13 de marzo, los partidos políticos eligieron a la juez de la Corte Suprema de Justicia Ertha PascalTrouillot como jefa del gobierno provisional. Finalmente, el 16 de diciembre de 1990 se celebraron las elecciones, en las que ganó Aristide, con el 67 por ciento de los votos. Antes de la toma de posesión, tuvo lugar un nuevo episodio que puso en peligro el ya de por sí frágil proceso: el 7 de enero de 1991, el ex ministro duvalierista del Interior y Defensa, además de connotado líder de los tonton macoutes, Roger Lafontant, anunció que había derrocado a Trouillot, pero tropas del ejército entraron en el Palacio Nacional, reponiendo al gobierno provisional.

No obstante las evidentes dificultades con que se desarrolló este período de búsqueda de una organización democrática de la sociedad haitiana, en 1987 se consiguió aprobar una nueva Constitución, que intentaba sentar las bases para una etapa distinta de la violenta historia política del país. En ella se establecía, entre otras cosas, que no podrían ser elegidos funcionarios aquellas personas que hubieran formado parte activa y consistente de los regímenes duvalieristas.

\section{ARISTIDE}

Aristide llegó a la presidencia habiéndose inscrito apenas dos meses antes de los comicios, con el respaldo del movimiento "Lavalás" (avalancha). El 7 de febrero de 1991 Aristide juró como presidente e inmediatamente anunció la reorganización del Ejército.

A la hora de elegir a sus colaboradores en el gobierno, Aristide dejó de lado a las fuerzas políticas que lo llevaron a la presidencia, lo que generó las primeras fricciones. Al mismo tiempo, comenzaron a darse algunas situaciones que ponían en duda el control del presidente sobre sus seguidores, que por primera vez actuaban sin miedo a las fuerzas represoras. Por ejemplo, algunos casos de ejecuciones de connotados tonton macoutes, con el método sudafricano del neumático en llamas. Estos hechos fueron exagerados por los enemigos de Aristide y por parte de la prensa de Estados Unidos, creando un clima adverso, en el que el presidente aparecía como un nuevo peligro para la convivencia pacífica y la viabilidad democrática.

Ocho meses escasos fue lo que duró Aristide en la presidencia. Fue derrocado el 30 de septiembre de 1991. Un 
día después pudo salir del país gracias al avión que le envió Carlos Andrés Pérez. Iniciaba así un exilio que comenzó en Venezuela y terminaría en Washington.

\section{LA RUPTURA DEL ORDEN CONSTITUCIONAL: EL GOLPE MILITAR Y LAS REACCIONES INTERNACIONALES}

Para dar el golpe de estado, los militares aprovecharon que Aristide volvía de su primer viaje al exterior, a la ONU y a Miami. El hombre clave fue el coronel Jean Michel Francois, jefe de policía de Puerto Príncipe, aunque al frente de la Junta Militar aparecerá el general Raoul Cédras. Francois era el hombre duro mientras que Cédras, un mulato claro, protestante, de maneras refinadas, aparecía como la cara amable, intentado apartar la desconfianza hacia un retorno a los métodos y formas del duvalierismo. Pero los hechos demostrarían lo contrario.

Como consecuencia del golpe, numerosos haitianos huyeron del país. Según datos del ACNUR, hechos públicos el 18 de septiembre de 1992 , unas 40.000 personas huyeron de la isla en una primera oleada. El coronel Francois volvió a dar vida a los tonton macoutes, esta vez bajo la apariencia de los llamados attachés o como integrantes de un grupo conocido como FRAPH (Frente para el Avance y el Progreso de Haití). En cualquier caso respondían a Francois, que eliminó todo atisbo de oposición política, mientras organizaba una impresionante red de corrupción que lo haría inmensamente rico. La represión se cobró entre 3.000 y 5.000 personas en los tres años siguientes.

La revista norteamericana The Nation (6 de octubre de 1994) publicó un informe en el que se aseguraba que agencias norteamericanas de inteligencia habían ayudado a formar el FRAPH tras el golpe. Según esta versión, el coronel Patrick Collins, agregado de Defensa en la embajada (entre 1989 y 1992), empezó a presionar al líder de los paramilitares, Emmanuel Constant, para establecer una organización que pudiera contrarrestar al movimiento de Aristide. Las discusiones de Constant con Collins comenzaron en septiembre de 1991 y desembocaron en el FRAPH. Esta versión fue negada por la embajada y por la CIA pero existe evidencia documental, confirmada en parte por Constant, en el sentido de que un grupo de attachés fueron pagados durante varios años por un proyecto norteamericano, que tenía archivos sobre los movimientos de los pobres de Haití. Algunos de estos attachés estarían implicados en algunos de los peores crímenes de Haití.

El golpe despertó en la comunidad internacional un repudio general, con la única excepción del Vaticano, primer estado que reconoció al nuevo régimen. Se sucedieron a partir de entonces distintas iniciativas internacionales. El 8 de octubre de 1991, la OEA impuso un embargo comercial contra el gobierno de facto, que sólo sería levantado con el retorno al poder del presidente constitucional.

El 24 de febrero de 1992, la OEA consiguió comprometer al parlamento de Haití para reinstaurar en el poder a Aristide. Este, por su parte, aceptaba como legítimas las decisiones tomadas por el parlamento desde la fecha del golpe. Ello suponía aceptar al general Cédras como jefe de las FFAA. Se llegó incluso a un acuerdo sobre la figura del que sería primer ministro, el comunista moderado René Theodore. El protocolo fue firmado por los presidentes del Senado, Dejean Belizaire, y de la Cámara de Diputados, Alexandre Medard. Ambos dijeron contar con el aval de Cédras, pero éste rechazaría después los acuerdos. El presidente "provisional", Joseph Nerette, manifestó que su gobierno no reconocía ningún protocolo y advirtió a los legisladores que su ratificación sería "inconstitucional".

Esta sería la forma de actuar habitual de los militares: negociar sin comprometerse a ningún acuerdo, o dar marcha atrás y desconocer los compromisos, en un intento de mantenerse a toda costa en el poder.

El 2 de junio de 1992, el Ejército produjo un golpe interno, al nombrar como nuevo primer ministro a Marc Bazin, que en las elecciones de diciembre de 1990 había obtenido el 14 por ciento de los votos. El 29 de septiembre de 1992, en su intervención ante la ONU, en la 47 Asamblea General, Aristide pidió que se pasara de las resoluciones a las acciones concretas para estrangular al régimen, haciendo un llamamiento a sus compatriotas a la resistencia activa y no violenta. Pero la condena internacional no surtio efecto y el embargo de la OEA no se cumplía.

El golpe planteó a Estados Unidos una nueva situación, con la huída en masa de los boat people haitianos hacia las costas de la Florida. La primera referencia pública sobre el tema por parte del entonces presidente Bush, fue para afirmar: "Haití es desde ahora, además de Cuba, el único país que impide al continente americano ser totalmente democrático". La cuestión de Haití se convirtió además en uno de los temas fundamentales de la campaña hacia la Casa Blanca. El candidato Clinton hizo promesas que sugerían una rápida acción contra los golpistas si era elegido. Tras su victoria no se cumplieron estas expectativas, pero se impusieron sanciones más severas.

El 4 de junio de 1993, el presidente Clinton decidió congelar los bienes en territorio de Estados Unidos de la cúpula gobernante y de las instituciones estatales, además de prohibir el ingreso a territorio norteamericano de los miembros del régimen de facto y quienes colaboraran con ellos. Se incluyó en la prohibición a 83 individuos, entre ellos Cédras y Bazin, 35 entidades y 4 bancos. Luego de conocerse las nuevas sanciones, Bazin anunció cuatro cambios en su gabinete. Pero poco después dimitió por enfrentamientos con los militares.

El 19 de octubre de 1993 comenzó el embargo de la ONU, con el apoyo de barcos de Estados Unidos y Canadá. Pero la avalancha de refugiados continuaba y acrecentaba el problema para Estados Unidos. El 8 de mayo de 1994 Clinton anunció que se detendría la llegada de boat people sin escuchar sus peticiones de asilo; los haitianos que huyeran podrían ser escuchados en buques en alta mar o en terceros países.

El 3 de julio de 1993, y tras siete días de negociaciones indirectas, delegaciones de Aristide y Cédras firmaron el Acuerdo de la Isla de los Gobernadores, que establecía el regreso de Aristide el 30 de octubre. Antes, las partes debían iniciar negociaciones políticas para la legalización del Parlamento, cuya elección, realizada el 18 de enero fue ca- 
lificada de ilegal; también se negociaría el nombramiento de un Primer Ministro por parte de Aristide y la dimisión, sin fecha determinada, de Cédras. La negociación política de los partidos con representación parlamentaria, tendría por objeto acordar una tregua y promover un pacto social, para asegurar una transición pacífica. Las sanciones impuestas por el Consejo de Seguridad de la ONU se levantarían inmediatamente después que asumiera el nuevo primer ministro. Habría amnistía para los militares golpistas y se aprobaría una ley para crear una nueva fuerza policial. El compromiso establecía el abandono de Cédras.

Pero el 11 de octubre de 1993, cuando aún estaba vigente el acuerdo de Isla del Gobernador, el FRAPH reunió a cientos de militantes para impedir el desembarco del "USS Harlan County", que llevaba tropas estadounidenses y canadienses para apoyar las gestiones de la ONU en el país, en tareas tales como la reconstrucción de carreteras, puentes, escuelas y hospitales. Se frustró de esta manera la vuelta de Aristide, generando una crisis internacional y nuevas sanciones contra Haití.

El 13 de octubre de 1993 el Consejo de Seguridad de la ONU votó unánimemente medidas similares a las que se impusieron a Iraq y Yugoslavia, incluyendo un embargo comercial total, que solo excluía alimentos, medicinas, libros, materiales de información, equipos necesarios para los periodistas y gas propano, usado para cocinar. Prohibía los vuelos aéreos, excepto los que tuvieran carácter humanitario. Prohibió también el abandono de Haití a 600 militares y oficiales de policía, sus familias y partidarios, sin un permiso especial, y se congelaron sus depósitos bancarios. De forma unilateral, el 10 de junio de 1994 el presidente Clinton decidió que en 15 días se interrumpiera el tráfico aéreo comercial con el país, prohibiendo además cualquier transacción financiera con Haití.

Días antes, los militares y el parlamento instalaron como presidente provisional al ex juez Emile Jonassaint, de 84 años. Invocando el artículo 149 de la Constitución, un puñado de senadores, la mayoría elegidos irregularmente en enero de 1993, proclamaron la vacante de la presidencia, en ausencia del jefe del Estado. Jonassaint había sido destituído de sus funciones como presidente de la Corte de Casación por el gobierno constitucional del Primer Ministro, Robert Malval. El nuevo presidente declaró el estado de emergencia, diciendo que la nación encaraba un extremo peligro y una posible invasión y ocupación. Decidió dar 48 horas a los observadores de derechos humanos de la ONU y OEA para abandonar el país, declarándolos personas non gratas, señalando que su misión era ilegal y amenazaba la seguridad nacional.

El 30 de julio de 1994 salió de Puerto Príncipe el último vuelo comercial, de Air France. Un día después, el Consejo de Seguridad de la ONU aprobó la resolución 940 (12 votos a favor, ninguno en contra y dos abstenciones, de Brasil y China), autorizando el uso de la fuerza para restaurar la democracia.

Desde el punto de vista de los derechos humanos y la economía, Haití se encontraba en estos momentos en una situación cada vez más desesperada. Un informe del secretario general de la ONU, Butros Gali, señalaba que desde el mes de julio la moneda había perdido el 40 por ciento de su valor, la inflación era galopante y el desabastecimiento estaba siendo cada vez más severo; los precios de los productos alimenticios básicos se habían más que doblado, y de acuerdo a economistas internacionales, casi el 80 por ciento de la población estaba en paro. Se afirmaba también que desde que una misión de derechos humanos fue expulsada el 13 de julio no había información de primera mano sobre la situación pero que, según organizaciones haitianas, sobre una lista parcial de violaciones cometidas en julio, se destacaban 41 ejecuciones extrajudiciales, 200 casos de arrestos arbitrarios, 76 casos de trato inhumano y degradante y 150 casos de búsquedas, además de varias formas de intimidación.

De enero a junio de 1994, la Misión Civil Internacional en Haití había comprobado unos 300 casos de ejecuciones extrajudiciales o de muertes sospechosas, de las que dos tercios de las víctimas eran dirigentes o militantes de organizaciones populares o allegados, en general partidarios de Aristide. La represión política, "que afecta a todo el país, se centra particularmente en los barrios populares (Cité Soleil, en Puerto Príncipe y Raboteau en Gonaives) y las localidades y zonas conocidas por su simpatía y apoyo a Aristide".

El 15 de septiembre de 1994, el presidente Clinton expresó en un discurso televisado a la nación que el general Cédras tenía que marcharse, que el tiempo había llegado, que todos los medios diplomáticos se habían agotado. Pero horas más tarde revivía la diplomacia al encomendar al ex presidente Carter, que había estado en contacto con Cédras, un último esfuerzo de paz.

Carter viajó a Puerto Príncipe con el general Colin Powell y el senador Sam Nunn, el 17 de septiembre a mediodía. La delegación cenó con hombres de negocios haitianos, quienes señalaron la conveniencia de que se hablara con la esposa de Cédras (Yannik), dada su notoria influencia. Al día siguiente visitaron la casa de Cédras, en el intento de encontrar una salida a la situación. A mediodía Clinton ordenó que la invasión comenzara esa medianoche. Un primer proyecto de acuerdo fue rechazado por Clinton porque no contenía fecha para la partida de Cédras y el alto mando. Powell insistiría ante Clinton que una vez que los americanos aterrizaran en Puerto Príncipe, este extremo perdería importancia. A media tarde, se incorporó inesperadamente a la reunión el general Biamby, quien acababa de ser informado de movimientos de las tropas norteamericanas. Acusó a los negociadores de traición y rompió las conversaciones. Carter continuó negociando con el presidente Jonaissaint y llegaron a un acuerdo que incluía la fecha del 15 de octubre para la partida de los militares. Pero ya era tarde para frenar el desembarco y, además, los militares se negaron a firmar el acuerdo, aunque dieron a Powell su palabra de soldados de que lo respetarían.

\section{LA OCUPACION NORTEAMERICANA Y LA RESTAURACION DE LA DEMOCRACIA}

El 19 de septiembre de 1994 comenzó la ocupación militar estadounidense. En los días siguientes, los jefes militares haitianos irían abandonando el país. El primero en hacerlo fue 
el jefe de la policía de Puerto Príncipe, el temido teniente coronel Joseph Michel Francois, para muchos el cerebro del golpe contra Aristide, y el hombre que controlaba el aparato represivo a través del FRAPH. El 9 de octubre de 1994 renunció el general Philippe Biamby, jefe de Estado Mayor. Y un día después lo hizo Cédras, quien en un mensaje ante el comando del Ejército, afirmó: "He decidido abandonar el país para que mi presencia no sea motivo para crear el terror".

El 15 de octubre de 1994 regresó a Puerto Príncipe el presidente Aristide, después de 1.111 días de exilio. Cuatro días más tarde, en su primera conferencia de Prensa, anunció un programa de 11 puntos que contemplaba, entre otras medidas, la profesionalización del Ejército, la separación de la policía, una democratización económica, una reestructuración del sector público, un acercamiento institucionalizado entre el estado y el sector privado, la dinamización de las relaciones de Haití con las instituciones financieras internacionales, y el fortalecimiento y reforma del poder judicial, y del parlamento, instaurando una oposición legal. Todo ello manteniendo el espíritu de su intervención en la ONU, días antes de su regreso a Haití: "prepararemos el café de la reconciliación, a través del filtro de la justicia, no encontraremos un trazo de violencia o de venganza".

El 8 de noviembre de 1994 asumió el primer ministro, Smarck Michel y se retomaron los esfuerzos para la instauración de una democracia en el país, en un contexto político, económico y social verdaderamente difícil: el regreso de Aristide se produjo en medio de un fuerte deterioro económico y social y con las huellas de una represión sangrienta todavía muy frescas.

Según cifras oficiales, el analfabetismo alcanza en Haití el 80 por ciento de la población. Apenas el 5 por ciento de los capitalinos acaparan más del 50 por ciento del ingreso nacional. El agua potable solo llega al 30 por ciento de la población. Cifras del Banco Mundial de 1988 indican que la renta per cápita era de 300 dólares al año; el 1 por ciento de la población concentraba el 46 por ciento del ingreso nacional; se calculaba entones que cerca del 80 por ciento de los haitianos ganaban menos de 100 dólares por año. Se calcula que en los últimos 5 años el costo de la vida aumentó cinco veces, mientras los salarios quedaban quietos. El salario mínimo industrial es de 35 dólares al mes. Puerto Príncipe acapara el 85 por ciento de la actividad industrial y el 65 por ciento de la comercial de todo el país.

Especialistas del Programa de las Naciones Unidas para el Desarrollo (PNUD) denunciaron el 20 de octubre de 1994 la degradación catastrófica del medio ambiente haitiano: "Hay demasiados pobres para el espacio utilizable y la pobreza y la miseria empujan a destruir el ambiente para sobrevivir". Según estadísticas hechas públicas, el 97 por ciento de la masa forestal ha sido destruída, no quedando más que 60.000 hectáreas de bosques. También se está produciendo una alarmante disminución del rendimiento de las tierras agrícolas. Los recifes coralinos están por ser asfixiados a causa de los sedimentos transportados por los cursos de agua. Y la mayoría de los sistemas de irrigación están destruídos. Ya en 1985 la ONU había advertido que "pocos países del mundo enfrentan como Haití una amenaza tan seria de catástrofe en materia ambiental, poniendo en juego, incluso, su supervivencia".

\section{EL PROCESO ELECTORAL}

En el mes de abril de 1995 el presidente Aristide anunció su decisión de desarticular el ejército, una vez que el Parlamento aprobara la necesaria enmienda constitucional. Esta decisión se tomaría después de las elecciones legislativas y municipales previstas, en principio, para diciembre. Pero las dificultades en la organización político-institucional del país hizo que la convocatoria electoral se aplazara dos veces: primero para el 4 de junio y luego para el 25 del mismo mes. El Consejo Electoral Provisional estableció que, en caso de que ninguna de las fuerzas consiguiera mayoría absoluta, se iría a una segunda vuelta el 16 de julio. Aunque algunos partidos de los 26 inscritos protestaron por el nuevo retraso, el calendario quedó fijado.

En conjunto, entre los grupos que conforman en la actualidad el mapa político de Haití, merecen destacarse los siguientes:

- Los dos grupos que apoyan al gobierno de Aristide son el Movimiento Lavalás, dirigido por Gerard PierreCharles, y el Frente Nacional para el Cambio y la Democracia, del ex alcalde de Puerto Príncipe, Evans Paul.

- Dos grupos centristas: el Movimiento para la Instauración de la Democracia en Haití, de Marc Bazin, y el Partido Agrícola Industrial Nacional, de Louis Dejoie.

- Existen dos grupos democristianos, el RDNP (Ressemblement des Démocrates Nationaux Progressistes), del ex presidente Leslie Manigat, y el Partido Demócrata Cristiano Haitiano, de Marie-France Claude.

- En la izquierda, los socialistas están divididos entre el Congreso Nacional de los Movimientos Democráticos (KONAKOM), de Víctor Benoit, y el Partido Nacional Progresista Revolucionario de Haití (PANPRA), de Serge Gilles.

- La oposición de derecha está compuesta por el MDN (Movilización para el Desarrollo Nacional), de Hubert de Ronceray, y el neoduvalierista moderado Movimiento Koumbite Nacional, de Volvick Rémy-Joseph.

- Más a la derecha se entra en la ilegalidad, ya que la Constitución de 1987 establece que no podrán ser elegidos funcionarios que hayan formado parte activa y consistente de los regímenes duvalieristas.

Pero el mapa político no se corresponde exactamente con el mapa electoral: los centristas de Marc Bazin, (MIDH) impugnaron la competencia del Comité Electoral Provisional y decidieron boicotear las elecciones. Por otro lado, la candidatura de los centristas de Claude Romain (Horizonte 2004) y una rama desgajada del Movimiento de Reconstrucción Nacional (MNR), dirigida por el comunista moderado René Théodore, fue rechazada por el CEP, decisión calificada como "totalmente arbitraria" por el socialista Serge Giles.

Entre los partidos autorizados por el CEP a participar en las elecciones figuran los dos partidos socialistas (KONAKOM y PANPRA); los centristas de Louis Dejoie (PAIN), el movimiento nucleado en torno al ex-presidente demócrata cristiano Leslie Manigat (RDNP) y el Partido Demócrata Cristiano de Marie-Denise Calude. Por su parte, el presidente Aristide apoya una coalición denominada "Movimiento Lavalás", formada por tres organizaciones 


\section{RECONCILIACION Y JUSTICIA}

Atendiendo a estos posibles resultados, los partidos minoritarios habían manifestado antes de las elecciones que "la oposición se tendrá que hacer en la calle". Pero una calle muy distinta a la de los tiempos de la dictadura, en la que la violencia y los asesinatos las sembraban de cadáveres. A pesar de cierto desacuerdo por parte de Estados Unidos, el Presidente Aristide sigue dispuesto a someter la propuesta de disolución del ejército al Parlamento. Entretanto, se ha creado la "Comisión de la Verdad", destinada a investigar asesinatos y desapariciones ocurridas tras el golpe de estado. Expertos de la Misión de las Naciones Unidas (MINUHA) colaboran en estas tareas y su presencia fue prorrogada hasta el 7 de febrero de 1996, es decir, cuando finaliza el mandato de Aristide.

La inflación descendió de un 52 por ciento en 1994 a un 24 por ciento (estimado) en 1995. Con un desempleo que ronda el 80 por ciento de la población activa, se espera alcanzar este año un crecimiento económico del 5 por ciento.
Ya han comenzado a ponerse en marcha planes de creación de empleo, muchas de las principales carreteras están siendo reparadas por primera vez en décadas. La tranquilidad parece haberse instalado, aunque el hambre y la pobreza siguen atenazando a una parte importante de la población.

Las soluciones para los serios problemas que aquejan al país no se lograrán fácilmente y los defectos que ha tenido el proceso electoral y el descontento suscitado en los partidos de la oposición no ayudarán a su consecución. El Presidente Aristide lo sabe y por ello insiste en sus intervenciones en que es necesario apoyar el proceso de "reconciliación y justicia" y que la minoría es tan necesaria como la mayoría: "necesitamos a los líderes de la oposición tanto como necesitamos a quienes apoyan al gobierno, necesitamos a los ricos tanto como a los pobres" (Herald Tribune, 22/9/95). Una ambigua llamada a la reconciliación, que debe garantizar que se llegue a las elecciones de diciembre y que el traspaso de los poderes presidenciales tenga lugar con todas las garantías. De ello depende buena parte de la supervivencia de la democracia en Haití.

\section{RESUMEN}

El presente artículo realiza un recorrido a lo largo de la historia reciente de Haití, centrándose en las circunstancias que rodearon la última ruptura del orden constitucional y el exilio del presidente Aristide. Después de reseñar la situación creada por el golpe militar de 1991, por la posterior reacción internacional y la ocupación militar norteamericana, los autores analizan la configuración de fuerzas políticas de la isla y los resultados de las elecciones legislativas y municipales celebradas el 25 de junio de 1995. Finalmente, reflexionan sobre las condiciones necesarias para la consolidación de la democracia en el país.

\section{ABSTRACT}

The present article realizes a review through the recent political history of Haití, focusing on the circumstances of the last breakdown of the constitutional order and the exile of President Aristide. After mentioning the problems created by the military coup of 1991, the later international reaction and North American military occupation, the authors analyze the configuration of political forces and the results of the legislative and local elections of 25 June 1995. Finally, they conclude about the necessary conditions for democratic consolidation in this country.

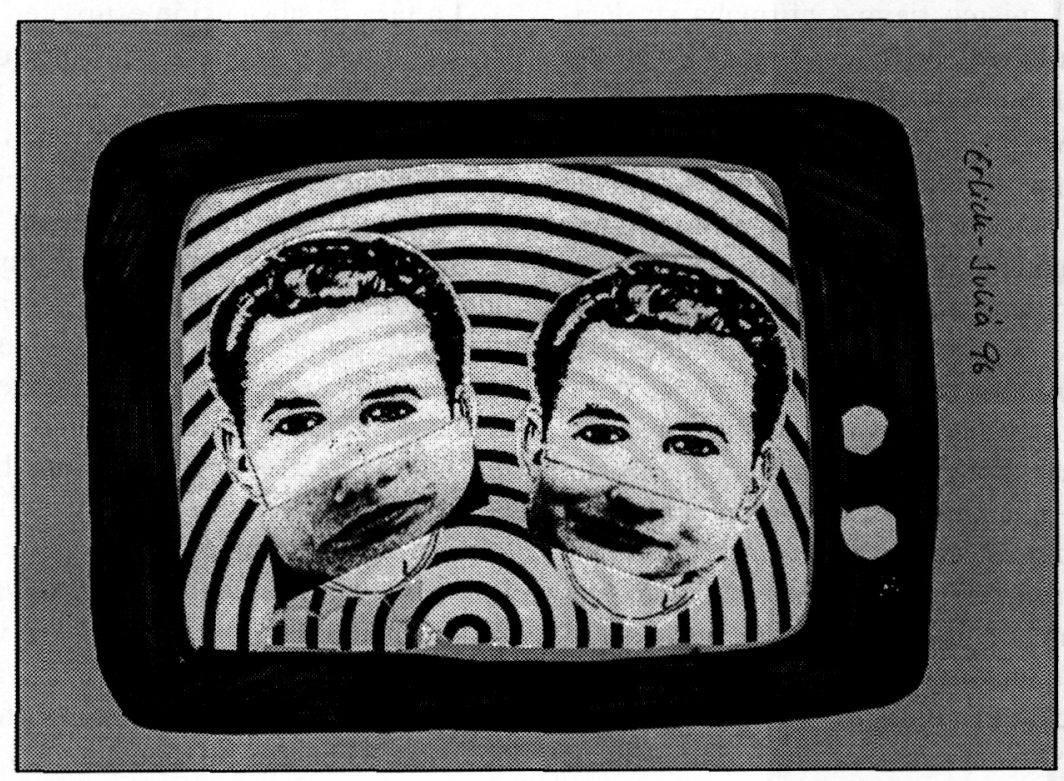


cercanas a su programa, que compite con sus antiguos aliados del Frente Nacional para el Cambio y la Democracia, quienes ahora se presentan solos.

Según las cifras del controvertido CEP, constantemente impugnadas por distintos partidos políticos, tres millones y medio de inscritos en el padrón electoral debían elegir a 18 senadores para la renovación de los dos tercios de la Cámara y 83 diputados (la totalidad). Al mismo tiempo se elegían 200 alcaldes y 525 concejales.

Un fuerte simbolismo marcaba a estas elecciones, a las que se presento - tanto interna como internacionalmentecomo un test sobre la democratización del país después del regreso de Aristide. En este sentido, las agencias de prensa difundían frases como la siguiente: "El domingo los haitainos demostrarán si el país se ha democratizado" (France Presse).

La movilización de observadores internacionales para garantizar que la elección fuera -en palabras de Aristide"honesta, libre y transparente", fue enorme: 400 personas de diversos organismos y países, incluyendo a las 30 que formaban la delegación norteamericana, para supervisar los comicios de los 10.031 locales que las autoridades instalaron en toda la isla.

En conjunto, las evaluaciones de la prensa y de los observadores internacionales coincidieron en que la campaña electoral se desarrolló en forma tranquila. La promesa de Aristide de desarticular el ejército después de las elecciones constituyó un punto clave de todo el proceso electoral: el 4 de junio, con ocasión de la jura de los primeros policías civiles, en lo que se denominó como una "ceremonia de la paz", Aristide subrayó la importancia de las elecciones puesto que "el nuevo parlamento deberá votar la supresión oficial del ejército". De todas maneras, la mayor parte de la oficialidad ya había sido pasada a retiro o depurada. Los restantes fueron agrupados en una "fuerza de policía interina" que será posteriormente disuelta y reemplazada por la nueva policía civil, dependiente del Ministerio de Justicia. Estos nuevos polícias están siendo formados por instructores norteamericanos, canadienses y franceses.

Finalmente, las elecciones tuvieron lugar el 25 de junio, en un clima que los observadores internacionales calificaron como "de tranquilidad y normalidad". No obstante, se denunciaron algunas irregularidades (en medio de cierto desorden que caracterizó a todo el proceso) y que daría lugar a que se repitiera la elección en algunas circunscripciones. El Consejo Electoral Provisional tardó casi tres semanas en dar los primeros resultados provisionales: todos los resultados apuntaban a un triunfo aplastante de Lavalás. El Consejo aceptó la validez de cuatro elecciones a senadores (de un total de 18), 16 diputados (de un total también de 18) y 80 de alcaldes (de 200). Según esos datos, el partido de Aristide había conseguido 70 alcaldías (entre ellas, la capital y las nueve ciudades más importantes del país) y todas las bancas legislativas válidas.

En Puerto Príncipe, la capital que alberga a un millón y medio de habitantes y que se disputaban 20 candidatos, el hombre de Aristide, el cantor Emmanuel (Mano) Charlemagne, habría obtenido 55.107 votos (el 45 por ciento del total) frente a su rival, el alcalde saliente Evans Paul (Frente Nacional para el Cambio y la Democracia,
FNCD), con 21.831 votos (el 18 por ciento). La importancia de este resultado no puede pasar inadvertida: Paul, líder indiscutido de una coalición de partidos moderados que apoyó a Aristide en las elecciones de 1990, tenía sus ambiciones puestas en las elecciones presidenciales previstas para diciembre de 1995. Su derrota, que lo coloca en un lugar incómodo, se debería - según diversos analistas- al desgaste que le ocasionó su permanencia en Haití tras el derrocamiento de Aristide y durante los tres años de dictadura militar, lo que le habría ocasionado cierto distanciamiento de sus bases.

El vencedor, Charlemagne, tiene 47 años, procede de una familia modesta de Puerto Príncipe, está casado y tiene cinco hijos. Se define a sí mismo como "un partisano de la teología de la liberación" y como un cantante folk comunista e independiente, amigo personal de Aristide, que adhiere al programa de liberalización económica del Presidente. La imagen a la que aparece asociado es la de un cantante popular que luchó y fue perseguido por la dictadura militar (en septiembre de 1991 solicitó refugio en la Embajada de Argentina y estuvo exiliado hasta el regreso de Aristide) y al que no le gustan las ingerencias de Estados Unidos (donde tiene una casa) en los asuntos de su país. Según los analistas, aparece muy asociado a las cuestiones de derechos humanos, más que a una agenda política concreta.

El programa con que se presentó a las elecciones se centró en la modernización y embellecimiento de Puerto Príncipe, con la rehabilitación de zonas desfavorecidas y proyectos concretos como el saneamiento del cementerio principal de la capital, la descentralización de las estaciones de autobuses y el arreglo de los paseos públicos. Su campaña electoral, simbólicamente, se centró en una guitarra y la dedicó en gran parte a dar recitales por toda América, Europa y Asia.

Los resultados fueron bastante bien aceptados por la población, pero un grupo de quince partidos, entre ellos el Frente Nacional para el Cambio y la Democracia (FNCD) y el Partido Nacionalista Progresista Revolucionario (PANPRA), decidió conjuntamente no participar en la repetición de los comicios en 21 circunscripciones electorales (en 8 de las 9 provincias) donde los resultados oficiales fueron destruidos o donde el 50 por ciento de las mesas no funcionaron. También se negaron a participar en la segunda vuelta (que se volvió a posponer, del 23 de julio al 13 de agosto). Estos partidos exigieron la anulación de las elecciones por entender que hubo "fraude generalizado" y la revocación del Consejo, calificándolo de "incompetente, ilegal y partidista", carente de credibilidad. Como dato ilustrativo de la forma en que se desarrolló todo el proceso electoral, cabe señalar que de los 27 partidos que concurrieron a las elecciones, 23 solicitaron en algún momento la anulación de los comicios por considerarlos fraudulentos. No obstante, los observadores internacionales insistieron en que los errores no beneficiaron a ningún partido en concreto.

Para complicar la situación, el CEP anunció que la repetición de la primera ronda en los 21 distritos impugnados se realizaría el día 6 de agosto, con la exclusión de 27 candidatos por haber sido acusados de agresiones y de "sabotear el proceso electoral". El malestar político se acrecentó, además, con la detención de un ex-diputado Duly 
Brutus, a mediados del mes de julio. Los temores sobre una posible salida dictatorial volvieron a surgir y diversos comentaristas políticos consideraban difícil para los responsables políticos haitianos dar por válidas las elecciones sin la participación de los partidos más importantes. Sin una participación plural, señalaban, se acrecienta el peligro de que Haití camine hacia una situación de partido único, que recordaría al parlamento duvalierista, "donde todo estaba votado antes de ser sometido al voto". Lo más importante para consolidar la frágil democracia haitiana era, a juicio de estos analistas, la consolidación de un sistema de partidos políticos que aseguren que todas las voces serán oídas.

Convencer a los múltiples y fragmentados partidos para que participaran en unas elecciones en las que sus posibilidades eran las de ganar apenas el 17 por ciento de las 101 bancas del parlamento, no se presentaba como una tarea fácil, en el contexto de la tradición política del país. No obstante, el Presidente Aristide convocó a una reunión a los líderes de varios partidos políticos para revisar el boicot a las eleciones complementarias. Los resultados del encuentro fueron confusos: sólo una formación admitía haber asistido (el KONAKOM) y sostuvieron que no se había alcanzado ningún consenso. Mientras el portavoz del gobierno declaraba que los líderes habían prometido cambiar su postura contraria a los próximos comicios, varios partidos pedían el cese del Consejo Electoral Provisional, por falta de garantías de imparcialidad y negaban haber asumido ningún compromiso. En este sentido se habían pronunciado Serge Gilles (PANPRA), Leslie Manigat (PRDNP) y Evans Paul (FNCD).

En la misma línea de calmar las aguas, Aristide admitía en una entrevista publicada por Le Monde el 25 de julio, que había habido irregularidades en las elecciones: "Lamento y condeno las irregularidades. Podríamos haberlo hecho mejor. Cuando las personas quieren votar y no pueden hacerlo porque no encuentran su colegio electoral, es grave. La reparación es necesaria". En la misma entrevista, llamaba a los demás partidos a participar, destacando la necesidad de que "el diálogo conduzca a la participación de varios partidos políticos en la segunda vuelta y en las próximas elecciones parciales, no hay otro camino. Un partido único, la ausencia de oposición, significaría la muerte de nuestra democracia". Al mismo tiempo afirmaba su decisión de no presentarse a la reelección presidencial: "el jefe del Estado se irá el 7 de febrero de 1996".

Pocos días después, Aristide introdujo cambios en el CEP, incorporando a un hombre de su confianza, Pierre-Michel Sajous, en reemplazo del anterior presidente del Consejo, Anselme Rémy, que renunció ante la avalancha de críticas recibidas y la falta de credibilidad ante una parte importante de las fuerzas políticas. Este nombramiento fue recibido por la oposición como una maniobra para reforzar el poder de la coalición gubernamental Lavalás y los tres partidos más importantes presentaron una propuesta alternativa que consistía en que renunciaran cinco miembros del CEP, con el objetivo de que los partidos con representación en las elecciones presentaran una lista de cuatro nuevos miembros y el quinto fuera designado por los demás partidos que participaran en el proceso. Al mismo tiempo hicieron un llamamiento a Aristide para encontrar una solución al conflicto. Mientras tanto, se mantendría la posición de boicot a las elecciones complemen- tarias que fueron retrasadas del 6 al 13 de agosto. Finalmente no se llegaría a ningún acuerdo y las elecciones complementarias tendrían lugar en un ambiente de apatía generalizada y una campaña marcada por el desinterés de la población. La Organización Política Lavalás (OPL) concurrió prácticamente sola a los comicios, en medio de una fortísima abstención. Los resultados le dieron 2 diputados más (ascendiendo a un total de 28), mientras que el número de senadores se mantuvo en 10 (sobre un total de 27).

Sobrepasadas las elecciones complementarias, comenzó la preparación de la segunda vuelta, fijada para el 17 de septiembre. Se iban a elegir 8 senadores y 56 diputados. Pero la situación política continuaba: un sector de la oposición continuó oponiéndose a las elecciones y exhortó al pueblo a la abstención electoral. Esta posición fue expresada con especial insistencia por los líderes del FNCD, Evans Pual y Turneb Delpé; este último calificó a los comicios como una "farsa" destinada a favorecer a la Organización Política Lavalás. Días antes de las elecciones, una coalición de 200 candidatos independientes confirmaron también su participación en el boicot, sumándose al reclamo de los principales partidos de la oposición para que se formara un nuevo y amplio consejo electoral.

A pesar de todo, el proceso siguió adelante, con la participación de 15 partidos políticos y 9 candidatos independientes: 15 candidatos para las 8 vacantes del Senado y 150 candidatos para los 56 escaños de los 83 que tiene la Cámara de Diputados. La campaña electoral pasó sin pena ni gloria, a pesar de los esfuerzos reiterados del gobierno por crear un clima de normalidad y limpieza electoral y por animar a la población a participar. Por su parte, los sindicatos haitianos anunciaron que un grupo de 150 trabajadores velarían por la limpieza del proceso electoral e intentarían motivar a la población para que participara en los comicios.

Nuevamente se produjo la movilización de los observadores internacionales: la Misión de Observación de la OEA se compuso de unas 200 personas y la Misión Civil Internacional, de unos 180 observadores. Además, los 6.000 soldados y los 900 policías de la Misión de las Naciones Unidas en Haití (MINUHA) se ocupan de la seguridad de las elecciones. Ambas misiones coincidieron en señalar que no hubo fraude en esta segunda ronda.

La tasa de abstención estuvo en torno al 70 por ciento. Tres fueron las explicaciones más esgrimidas frente a esta baja participación: por un lado, el hecho de ser la tercera convocatoria electoral en un plazo de tres meses, con el consiguiente cansancio de la población frente a una especie de estado de "votación permanente"; complementario a ésto, se esgrime el argumento de que para el conjunto del pueblo haitiano las elecciones verdaderamente importantes fueron las primeras, ya que suponían una manifestación clara de rechazo a la dictadura reciente y de apoyo a la nueva etapa, siendo las siguientes (tanto la complementaria como la segunda vuelta) cuestiones más bien secundarias. Por el lado de la oposición y de su negativa a participar, la abstención es un síntoma de la falta de credibilidad y el clima fraudulento en el que tuvo lugar todo el proceso electoral.

En cualquier caso, los que sí votaron confirmaron la preferencia por la Organización Lavalás: el Presidente JeanBertrand Aristide se hizo con el control de ambas cámaras, 66 de las 83 bancas de diputados y 17 de las 27 del Senado. 